\title{
Laboreal
}

Volume $11 \mathrm{~N}^{\circ} 1$ | 2015

Modos de vida e trabalho

\section{Reflexões sobre a metodologia da clínica da atividade: diálogo e criação no meio de trabalho}

Reflexiones sobre la metodología de la Clínica de la actividad: diálogo y creación en el ambiente de trabajo

Réflexions sur la méthodologie de la Clinique de l'Activité: le dialogue et la création en environnement de travail

Reflexions on the methodology of the activity clinic: dialogue and creation in the work environment

Alice Paiva Souto, Karla Maria Neves Memória Lima e Claudia Osorio da Silva

\section{OpenEdition}

Journals

Edição electrónica

URL: http://journals.openedition.org/laboreal/3962

DOI: $10.4000 /$ laboreal.3962

ISSN: 1646-5237

Editora

Universidade do Porto

Refêrencia eletrónica

Alice Paiva Souto, Karla Maria Neves Memória Lima e Claudia Osorio da Silva, «Reflexões sobre a metodologia da clínica da atividade: diálogo e criação no meio de trabalho », Laboreal [Online], Volume $11 N^{0} 1$ | 2015, posto online no dia 01 julho 2015, consultado o 08 outubro 2019. URL : http:// journals.openedition.org/laboreal/3962 ; DOI : 10.4000/laboreal.3962

Este documento foi criado de forma automática no dia 8 outubro 2019.

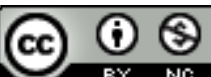

Laboreal está licenciado com uma Licença Creative Commons - Atribuição-NãoComercial 4.0 Internacional. 


\section{Reflexões sobre a metodologia da clínica da atividade: diálogo e criação no meio de trabalho}

Reflexiones sobre la metodología de la Clínica de la actividad: diálogo y creación en el ambiente de trabajo

Réflexions sur la méthodologie de la Clinique de l'Activité: le dialogue et la création en environnement de travail

Reflexions on the methodology of the activity clinic: dialogue and creation in the work environment

Alice Paiva Souto, Karla Maria Neves Memória Lima e Claudia Osorio da Silva

\section{NOTA DO EDITOR}

http://dx.doi.org/10.15667/laborealxi0115aps

Manuscrito recebido em: novembro/2014

Aceite após peritagem: maio/2015

Agradecemos a leitura atenta desse artigo à amiga Tatiana Ramminger, professora e chefe do Departamento de Psicologia na Universidade Federal Fluminense, polo de Volta Redonda-RJ. No processo de elaboração do texto, seus comentários foram muito importantes. A gratidão à amiga já era clara quando um triste acontecimento deu a esse sentimento grande intensidade. Tatiana Ramminger, uma jovem professora talentosa, vibrante e livre, faleceu no dia 14 de novembro de 2014, aos 41 anos, em acidente fatal numa rodovia da região em que morava e trabalhava. Foi enriquecedor ter contado com sua parceria e muito triste ter perdido precocemente essa pesquisadora e militante ativa da saúde no Brasil. 


\section{Introdução}

1 Este artigo apresenta uma discussão teórica sobre a criação na atividade de trabalho. Busca-se compreender a emergência do novo na atividade de trabalho por meio dos conceitos de criação e desenvolvimento no âmbito da psicologia históricodesenvolvimental, tal como ela é tomada pela clínica da atividade.

2 No Brasil, nas décadas de 1980 e 1990, os estudos do trabalho foram marcados por grande interesse, na área da Saúde Coletiva, por temas relativos a saúde e segurança no trabalho (Minayo-Gomez, 2011). Esses estudos incorporaram como um eixo estruturante da sua compreensão do trabalho o patrimônio da ergonomia francofônica, ao mesmo tempo que dialogavam com os debates sobre a saúde na Itália, em que se destacaram as contribuições de Giovanni Berlinguer (Mendes \& Dias, 1991) nos debates sobre a saúde pública e de Ivar Oddone e seu grupo nas discussões da saúde na fábrica (Brito, 2004).

3 Nesse caminho, as chamadas clínicas do trabalho ganharam relevo no campo da psicologia do trabalho. Ganharam visibilidade autores como Christophe Dejours e, adiante, Yves Schwartz e Yves Clot (Neves, Seligmann-Silva \& Athayde, 2004; Bendassoli \& Soboll, 2011).

4 Às autoras desse artigo interessaram as contribuições de Yves Clot, no que ele denomina clínica da atividade (Clot, 2007). Nesta formulação o conceito de desenvolvimento é central. Em diálogo com uma grande rede de outros pesquisadores, busca uma formulação teórico metodológica que retoma e desenvolve algumas linhas dos estudos já mencionados. A retomada que se faz se justifica pela necessidade de construção de instrumentos que possibilitem intervir nos ambientes de trabalho de modo a contribuir para o desenvolvimento de recursos para a ação, destacando como inspirador e aliado Ivar Oddone e sua ética. Para Oddone, os psicólogos do trabalho não devem funcionar como experts que indicam os caminhos tecnicamente corretos, mas assessorar os trabalhadores para que, com seus conhecimentos, adquiridos no chão de fábrica, possam ultrapassar alguns dos problemas que enfrentam (Clot, 1981). Afirma-se assim o objetivo de contribuir para que os trabalhadores alcancem uma ampliação de seu poder de agir. Se este objetivo sustenta a produção de instrumentos para a intervenção, os objetivos teóricos se centram no estudo do desenvolvimento dos meios para a ação que indicam a ocorrência da ampliação desejada.

5 O conceito de desenvolvimento é tomado de Vigotski, que é lido tendo Bakhtin como interlocutor privilegiado (Clot \& Faïta, 2000; Clot, 2010a). No corpo teórico que assim se constitui, numa releitura que busca valorizar todo um patrimônio, não se pode pensar o desenvolvimento sem pensar a criação: a criação de recursos para a ação.

6 De acordo com a clínica da atividade, é possível afirmar que o poder de (re)criação no meio de trabalho se desenvolve a partir da apropriação dos recursos para a ação elaborados no coletivo. Os métodos propostos visam a revitalização da atividade dos trabalhadores, bem como a produção de conhecimento sobre esse processo. Considerando que estes processos de desenvolvimento de meios de ação não são diretamente observáveis, utilizam-se métodos indiretos de análise. A análise se faz a partir de marcas do trabalho, que podem ser falas e/ou imagens registradas em áudio, vídeo, fotografias ou outros modos de registro que vierem a ser propostos [1]. 
7 O termo 'indireto' explicita a relação da metodologia da clínica da atividade com a perspectiva histórico-desenvolvimental, que tem Lev Vigotski como um de seus principais autores. A apropriação que se faz da obra de Vigotski sofre interferências da leitura de Bakhtin (2006). Os dois autores participam de uma mesma linhagem epistemológica, fundamentando-se no materialismo histórico-dialético para a construção de suas perspectivas (Barros, 2012). Tanto Bakhtin quanto Vigotski criticam a psicologia idealista e descolada da história e da sociedade (Martins, 2009). A partir desta concepção filosófica, o conceito de atividade humana está vinculado às bases materiais da existência.

8 Assim, a atividade conscientemente orientada só é possível decorrente das relações sociais, engendrada na história dessas relações, mediada por instrumentos e signos. A perspectiva de Vigotski (2009) enfatiza o potencial gerador e transformador da atividade criadora, o que dá viabilidade para o humano planejar, projetar e construir suas próprias condições de existência.

Clot (2010a) se alia a Vigotski, pensador que buscou princípios explicativos para o desenvolvimento no estudo das leis gerais da gênese da criação na infância. A clínica da atividade apropria-se desses princípios para compreender o caráter inventivo próprio à atividade de trabalho, visto que Vigotski formula que o desenvolvimento se dá pela mediação e que este processo permanece por toda a vida, não se restringindo à infância.

10 A psicologia histórico-desenvolvimental destaca a natureza social das funções psíquicas superiores, como o pensamento lógico, a memória consciente e a vontade. Estas são funções especificamente humanas, que não se apresentam prontas ao nascer. Esta perspectiva enfatiza que o desenvolvimento ocorre ao longo do processo de assimilação dos sistemas de signos em que as funções psíquicas biológicas transformam-se em novas funções: as funções psíquicas superiores. Este processo ocorre ao longo de toda a vida e se dá na relação com o meio, embora possa ser mais ou menos potencializado dependendo da idade em que ocorre (Prestes, 2012).

11 Nesse artigo interessa-nos pensar o conceito de criação. Com esse objetivo, retomamos alguns escritos de Vigotski $(1996,2002,2009)$ e outros que apresentam Vigotski lido por Yves Clot. Usamos também escritos de pesquisadores brasileiros contemporâneos como Prestes (2012), Smolka (2009) e Zanella (2007).

12 Nesse percurso estamos em um diálogo, na sua maior parte interior, com os experimentos que temos feito, em nosso grupo de pesquisa no Brasil, em especial com o dispositivo da Oficina de fotos.

\section{A história do desenvolvimento como objeto e método}

\subsection{0 foco nas relações como estratégia metodológica}

13 Vigotski, nas décadas de 20 e 30 do século XX, enfatizou "que todos os fenômenos [psicológicos] sejam estudados como processos em movimento e em mudança" (2002, p. 8). 0 pesquisador analisa processos e movimentos. Ao invés de isolar elementos a serem conhecidos, a metodologia da psicologia histórico-desenvolvimental opta pelo foco nas relações, que viabiliza a compreensão da totalidade. Nessa metodologia, são estudados 
os fenômenos na história, ou seja, movimentos de recriação da realidade que se dão através de mudanças nas relações (Zanella, Reis, Titon, Urnau \& Dassoler, 2007).

A partir desta compreensão, a clínica da atividade define como objeto a história do desenvolvimento da atividade de trabalho e seus empecilhos. No âmbito da relação objeto/método, isto leva à proposição de instrumentos com os quais os trabalhadores, em relação com seus pares e outros interlocutores - pesquisadores e clínicos do trabalho - possam se avaliar diante do que fazem. Trata-se de um método de ação que propõe uma experiência de parceria entre o pesquisador ou clínico do trabalho com o trabalhador, tendo em vista a análise do próprio meio de trabalho.

[Um método] concebido, não para saber o que são, mas para experimentar, com eles [os trabalhadores], o que poderiam vir a ser. Em vez de procurar a explicação do que é eterno, a psicologia de Vigotski tenta encontrar as condições gerais mediante as quais se produz algo de novo (Clot, 2010a, p. 63-64, grifo do autor).

Nas experimentações que caracterizam a metodologia, busca-se provocar uma intensificação dos processos de surgimento do novo, para que seja possível estudá-los. Há uma relação inexorável entre objeto e método de investigação: a construção do método é, ao mesmo tempo, premissa e produto, ferramenta e resultado da investigação.

16 A experimentação se dá no diálogo sobre a atividade. O foco no movimento e nas relações, que pode ser encontrado na obra de Vigotski, se apresenta na análise da constituição do pensamento verbal como uma relação entre pensamento e linguagem (Zanella et al., 2007). 0 uso de signos, como na fala, tem uma função organizadora que invade o processo de elaboração e uso dos instrumentos, produzindo novas formas de comportamento e percepção.

\subsection{0 papel da fala como produtora de novos modos de percepção}

17 A observação do desenvolvimento infantil possibilita uma melhor compreensão deste processo. De acordo com Vigotski, a criança começa a controlar o ambiente com a ajuda da fala, o que produz novas ligações com o ambiente e com relação a seu próprio comportamento.

\footnotetext{
... as crianças resolvem suas tarefas práticas com a ajuda da fala, assim como dos olhos e das mãos. Essa unidade de percepção, fala e ação, que, em última instância, provoca a internalização do campo visual, constitui o objeto central de qualquer análise da origem das formas caracteristicamente humanas de comportamento (2002, p. 35).
}

18 A criança, quando se encontra diante de um problema prático, utiliza a fala para sua resolução, uso que se torna mais intenso quanto mais complicada é a situação. Nesse contexto, qualquer tentativa de impedir a fala da criança corre o risco de paralisá-la. A criança percebe o mundo não somente através dos olhos, mas igualmente através da fala, que adquire uma função sintetizadora.

19 Considerando a fala como produtora de novos modos de percepção, é possível compreender que a transformação e o desenvolvimento dialógico geram também novos modos de conhecer e sentir que, por sua vez, serão essenciais para a criação de novas possibilidades nesse meio. A fala em voz alta ou, com o desenvolvimento, em diálogo 
interior, é facilitadora da relação com o meio. Com a interação com outro(s), na relação social, esse movimento se intensifica.

\title{
2.30 movimento dialógico como criação de novas relações e ampliação do poder de agir
}

Segundo Clot (2010a, p. 137), que nessa análise acompanha Darré em sua leitura de Bakhtin sobre o meio de trabalho, o diálogo como instância de desenvolvimento se alimenta de outros diálogos anteriores e paralelos existentes no grupo profissional. As experiências de outros profissionais se fazem presentes por meio do diálogo, de modo que é possível ampliar o repertório de possibilidades de compreender e de agir na situação de trabalho, desenvolvendo a atividade.

\begin{abstract}
O movimento dialógico cria: relações renovadas, de situação em situação, entre o falante sujeito e os outros, assim como entre esse mesmo falante e aquele que ele havia sido na situação precedente, além do modo como ele o havia sido. Procedendo assim, ele transforma, manifesta e revela, no sentido fotográfico do termo, as posições dos interlocutores que se elaboram no decorrer do movimento, até mesmo se desestruturam sob efeito das contradições engendradas por esse mesmo movimento dialógico. Falar-se-á então de uma motricidade própria ao diálogo (Clot, 2010a, p. 135, grifo do autor).
\end{abstract}

21 Por meio do diálogo, o analista do trabalho, como novo interlocutor, busca mobilizar a experiência estabilizada como meio de viver novas experiências e desenvolver novos recursos para a ação. Há um aumento no poder de agir, conceito apropriado por Clot e Faïta (2000) da filosofia de Espinosa [2]. Segundo os autores, quanto maior o poder de ser afetado pelas diversas atividades da qual se é sujeito, maior a vitalidade dialógica.

Nessa perspectiva, é preciso desenvolver o diálogo tornando-se ativo em seu exercício. Como um dos efeitos do recurso dialógico no processo de apropriação da alteridade que nos afeta, é possível transformar a passividade em atividade. Caso contrário, na tentativa de enclausuramento da alteridade, o sujeito fica exposto aos riscos da doença mental.

Considerando a relação intrínseca entre pensamento e linguagem, é possível compreender o sujeito como um ser heterogêneo que vive constantemente um diálogo interior. Desse modo, a metodologia da clínica da atividade busca, através da abertura deste diálogo, gerar novas formas de percepção e mudança nas relações do sujeito, no âmbito da atividade profissional.

Para tal, é indispensável a mobilização do coletivo de trabalho, considerando que " $a$ abertura ao diálogo interior não pode manter-se sem relé social que o alimenta em energia conflitante" (Clot, 2010a, p. 33, grifo nosso). Parte-se de uma concepção das relações entre o sujeito e o coletivo na qual se destaca a importância da controvérsia como geradora de desenvolvimento. Levando adiante essa intuição, afirma-se que há um encolhimento do funcionamento psíquico quando a sociedade se torna monológica deixando de oferecer a energia conflitante que alimenta a vitalidade do diálogo.

A metodologia em clínica da atividade busca dar maior intensidade à controvérsia, trazer para o diálogo proposições, suas variações, concordâncias e principalmente divergências, para que desse embate possam surgir novos enunciados. 
Nesse viés, o método proposto para análise do trabalho pode tornar-se o disparador de mudanças do sentido da atividade, viabilizando novas significações ao desmontar sentidos que impediam a atividade e, com isso, ampliar os recursos para a ação.

\section{0 gênero da atividade profissional e as múltiplas possibilidades dialógicas na situação de trabalho}

27 Segundo Bakhtin (2006), todos os diversos campos da atividade humana estão ligados ao uso da linguagem. Cada campo de utilização da língua elabora seus tipos relativamente estáveis de enunciados, que são denominados gêneros do discurso. Existe uma diversidade inesgotável de formas de gênero discursivos, que crescem e se desenvolvem nos diversos campos da atividade humana. Entre eles, tanto os gêneros do discurso comum, orais e escritos, por exemplo: réplicas do diálogo do cotidiano, cartas, manifestações publicísticas e etc.; como as variadas formas das manifestações científicas e todos os gêneros literários. A partir da concepção de Bakhtin, Clot e Faïta (2000) desenvolvem o conceito de gênero de atividade profissional, segundo o qual há, não só uma linguagem própria a cada ofício no âmbito da atividade do trabalho, como também um sistema simbólico que organiza a ação individual na relação com as normas do ofício.

Para Bakhtin (2006), todo enunciado é antecedido pelo enunciado de outros e depois de seu término, sucedido pelos enunciados responsivos de outros. Do mesmo modo, a atividade de uma pessoa é sempre dialógica e inacabada. Ela é sempre atravessada por outras atividades, funcionando como uma resposta possível a estas. A atividade é triplamente dirigida: 1) Por meio de seus objetos de trabalho; 2) Aos outros, depois de ter sido destinatária da atividade destes e antes de o ser de novo; 3) Pelo comportamento do sujeito, que implica em um diálogo consigo mesmo e nas outras duas direções anteriores (Clot, 2010b).

O conceito de subdestinatário é utilizado por Clot (2010a) para designar as vozes internas do "pequeno diálogo" interior, estimulado pela observação (que pode ser a do analista do trabalho). Contudo, há também uma dimensão mais ampla, um "grande diálogo" que se refere ao seu caráter transpessoal. $\mathrm{O}$ autor destaca a interferência entre as réplicas do diálogo aparente - aquele que ocorre, em voz alta, entre duas ou mais pessoas na situação comunicacional - e do diálogo interior. O diálogo não se encontra restrito a uma situação comunicacional específica. $O$ autor de um enunciado dirige sua comunicação a um destinatário concreto do diálogo realizado. Entretanto, todo diálogo se desenrola na presença de um terceiro que não está fisicamente presente, trata-se do sobredestinatário, que se inscreve em uma história coletiva - na história do ofício ou do gênero profissional. Esta dimensão viabiliza uma instância de justificação que protege o locutor de uma avaliação imediata. De acordo com Bakhtin, tal dimensão é tocada por exemplo quando, diante de uma mentira, alguém afirma: "Qualquer pessoa, no meu lugar, teria mentido". Por meio dessa frase é possível vislumbrar, na situação dialógica, alguma coisa que está para além da relação entre o locutor e o destinatário da comunicação.

30 É importante ressaltar que todo diálogo é inacabado, uma vez que a palavra atravessa seu destinatário imediato, de modo que um enunciado pode entrar em diálogo em outro 
tempo ou espaço. A palavra está destituída de fundo porque ela não possui um único sentido, não tem fim em si mesma, estando aberta a múltiplas possibilidades dialógicas.

\section{A metodologia indireta e dialógica da clínica da atividade}

\subsection{O processo de criação e recriação de meios para a ação como objeto de análise}

31 A metodologia da clínica da atividade repousa fundamentalmente sobre a distinção entre a atividade realizada e o real da atividade. Essa diferenciação remete à clássica diferença, formulada nos estudos da ergonomia situada, entre tarefa e atividade.

Inicialmente, pode-se dizer que a tarefa é aquilo que é o que deve ser feito em um processo de trabalho específico e em uma situação dada, destacando-se as regras e os objetivos fixados pela organização do trabalho.

33 Leplat (1980, p. 27-29) define atividade como a resposta do indivíduo ao conjunto de condições de trabalho, consideradas em sua amplitude e complexidade. A atividade se dá no plano físico, ou motor, sendo ela observável, e no plano cognitivo, não observável, devendo então ser analisada por inferência, a partir de diversos traços. 0 autor assinala que a atividade tem consequências sobre o sistema técnico, sobre o objeto do trabalho e sobre o próprio trabalhador. 0 conjunto de condições de trabalho, intervindo na atividade, constitui a tarefa, que pode ser definida também como um objetivo a atingir sob certas condições. A atividade não pode ser simplesmente deduzida da tarefa, uma vez que existem muitas maneiras diferentes de responder a uma mesma tarefa. As maneiras de executar uma tarefa variam para cada sujeito e variam também para um mesmo trabalhador, de acordo com a situação. Tarefa e atividade estão sempre em estreita relação, de tal modo que a análise do trabalho será marcada por passagens sucessivas da análise da tarefa à da atividade e vice-versa, cada uma se enriquecendo da outra.

O trabalho é, em parte, passível de ser prescrito, previsto e percebido do exterior, como comportamentos ou gestos. Mas as prescrições são recursos incompletos, por vezes contraditórios, exigindo e propiciando aos trabalhadores uma participação ativa nesse processo. Os coletivos de trabalho enfrentam essa tensão com recursos técnicos e éticos que são historicamente construídos, sustentando sua atividade.

$\mathrm{Na}$ atividade os trabalhadores se confrontam com os conflitos, devendo buscar os caminhos desejados entre os possíveis da atividade e criar novos caminhos, novos possíveis, a fim de enfrentar o que seria impossível. Essa criação se dá nos diálogos, entre sujeito, objeto de trabalho e colega(s) de trabalho, que constituem a atividade, concebida como atividade dirigida.

Mas um aspecto merece atenção: o possível, nessa tríade [da atividade dirigida] não é intrínseco ao objeto, ao sujeito nem aos outros. É em primeiro lugar entre eles que se tem que buscá-lo se se desejar ter alguma chance e encontra-lo neles (Clot, 2007, p. 116). 
O processo de desenvolvimento de novos possíveis no trabalho se dá no coletivo e inclui processos aos quais não se tem acesso direto. Buscando ferramentas conceituais para dar conta deste problema metodológico, Clot propõe o conceito de real da atividade.

... o real da atividade é também aquilo que não se faz, aquilo que não se pode fazer, aquilo que se busca fazer sem conseguir - os fracassos -, aquilo que se teria querido ou podido fazer, aquilo que se pensa ou que se sonha poder fazer alhures. É preciso acrescentar a isso - o que é um paradoxo frequente aquilo que se faz para não fazer, aquilo que se tem que fazer ou ainda aquilo que se faz sem querer. Sem contar, aquilo que se tem que refazer (2007, p. 116).

Seguindo esse argumento, o real da atividade excede à atividade realizada. De acordo com a definição acima, a atividade realizada é o resultado do conflito entre as várias atividades possíveis e rivais. Aquilo que se pode observar como a atividade do trabalhador é, na verdade, o conjunto de atividades que venceram o conflito entre as diversas atividades possíveis. Contudo, as atividades inibidas, que são de grande importância para a compreensão da atividade realizada, não são observáveis diretamente. Desse modo, a atividade real deve ser abordada através de métodos indiretos.

\subsection{Metodologia indireta: o diálogo como meio para desenvolver e analisar o trabalho}

Vigotski (1996) afirma que constitui um grave erro pensar que a ciência só pode estudar o que nos mostra a experiência direta. Mesmo nas ciências experimentais, como na física óptica, por exemplo, aparelhos de percepção e mensuração, como o detector de ondas, o barômetro, o radiômetro e outros, permitem operar com métodos em que o olho não intervém. Quando as ciências estudam fenômenos que não se oferecem ao conhecimento direto, em geral elas reconstroem e elaboram seu objeto de estudo recorrendo ao método de explicar ou interpretar seus vestígios. Desta forma, um historiador interpreta vestígios - documentos, memórias, jornais - e a partir deles reconstrói a história que não viveu diretamente. Também o clínico da atividade faz uso de métodos indiretos para analisar o trabalho, uma vez que a atividade não pode ser observada diretamente.

Segundo Vigotski, a atividade humana é necessariamente mediada, o que remete ao conceito de trabalho humano, tal como proposto pela teoria marxista. A mediação é uma consequência da condição do homem enquanto ser social, ou seja, o homem se relaciona com a natureza e com outros homens através de algo que faça a mediação e não de maneira direta. De acordo com a perspectiva dialética, o trabalho é mediatizado pelos instrumentos, que, por sua vez, são um produto historicamente construído pela atividade social humana. Estes instrumentos podem ser de natureza física, como no caso de ferramentas que modificam o meio físico; e representacional, que seriam os signos os quais incidem e modificam a relação do homem consigo e com os outros homens (Zanella, 2007). O principal sistema de signos é a linguagem e é por meio dela que é explicada a constituição do sujeito e do mundo ao seu redor.

No caso da linguagem oral, o signo da fala deve ser partilhado socialmente para que seja compreendido em uma construção coletiva de sentido. "De acordo com a perspectiva 
vygotskiana, o nosso contato com o mundo físico e social não é direto, é na verdade marcado por aquilo que significamos desse próprio mundo" (Zanella, 2007, p. 77), o que cria uma relação indireta da pessoa com a realidade, marcada pelas experiências e possibilidades.

Os signos são importantes mediadores da atividade. Assim, considera-se que métodos que produzem fala - diálogo - sobre o trabalho produzem atividade sobre esse mesmo trabalho, desenvolvendo-o.

O método indireto ao considerar o real da atividade, e não somente a atividade realizada, permite analisar os conflitos vitais inerentes ao trabalho, que podem tornar ou não, seu desenvolvimento possível. As possibilidades descartadas, tão importantes para compreender aquelas que se realizaram, não são acessíveis diretamente. Elas são despertadas através da reflexão sobre as ações no trabalho. Uma vez que a ação passa pelo crivo do pensamento, ela já se transforma em outra ação. Considerando a mediação do pensamento pela linguagem, esta reflexão se efetua no meio social, através de uma metodologia dialógica (Clot, 2010a; Faïta, 2007; Faïta, 2013).

\subsection{Métodos que disparam e intensificam o diálogo}

43 Na metodologia da clínica da atividade, os métodos são propostos como dispositivos [3] que visam disparar e potencializar diálogos sobre a atividade. 0 efeito pretendido é que, com a entrada de um novo interlocutor, o analista do trabalho, haja a intensificação do diálogo interior dos trabalhadores, destes com seus pares e também o diálogo com o sobredestinatário, o gênero profissional. Assim, temos acesso a aspectos implícitos das diferentes atividades que compõem o trabalho. $O$ analista do trabalho e os trabalhadores, protagonistas da atividade, travam um diálogo sobre situações já familiares que estes selecionam para colocar em análise. A partir destas marcas do trabalho, o profissional se observa e assume uma posição de protagonismo diante de sua atividade. $O$ analista atua, nesse cenário, como coadjuvante, ou seja, como um dos instrumentos mediadores da análise.

No método da autoconfrontação cruzada (Clot \& Faïta, 2000; Fernandez \& Clot, 2007), por exemplo, os profissionais são confrontados com a imagem de seu trabalho gravado em vídeo. Nesse sentido, as imagens funcionam como o meio de convocar o pensamento, portanto, de produzir novas ações sobre a atividade.

Do mesmo modo, na oficina de fotos (Osorio, 2010, 2011), os trabalhadores participantes são confrontados com imagens fotográficas, nesse caso registros do trabalho produzidos por eles mesmos. A oficina de fotos tem sido usada como um método para o desenvolvimento do poder de agir dos coletivos de trabalho em cenários variados (Teixeira, 2008; Osório, 2010; Pacheco, Barros \& Osorio da Silva, 2013; Souza, 2012; Alves, 2013; Louback, 2013). Este dispositivo lança mão do recurso da fotografia fazendo com que o processo de produção da imagem se dê também como processo de análise da atividade. As fotos são feitas pelos trabalhadores, protagonistas da atividade. Em seguida, as fotografias são postas em debate entre os trabalhadores, com o analista do trabalho convocando ao diálogo sobre a atividade que se desenvolve em torno dos modos coletivos de produzir e vivenciar o trabalho.

A proposição da oficina de fotos como um dispositivo em clínica da atividade acompanha também a formulação da análise institucional francesa, ou seja, um dispositivo que produz intervenção (Coimbra, 1995; Osorio, 2010). Com isso, a oficina de 
fotos é um método que também pode ser pensado como um analisador construído, que transforma para compreender e compreende para transformar, criando possibilidades para a ampliação dos recursos para a ação.

Na proposta metodológica aqui considerada, a observação, que faz parte dos métodos em geral de análise do trabalho, toma uma função específica: a de favorecer o deslocamento dos trabalhadores para o lugar de observadores de si e de seu próprio fazer, provocando o diálogo interior.

\subsection{A observação como estratégia metodológica para um deslocamento do olhar}

Clot (2010b) afirma que a observação nos ambientes de trabalho gera um duplo resultado. O primeiro está ligado à produção de conhecimento sobre o objeto observado, a atividade, acompanhando uma tradição já bem desenvolvida pela ergonomia e outras abordagens que valorizam os estudos situados do trabalho. 0 segundo relaciona-se ao fato de que a observação já produz uma intervenção no campo, ao produzir um diálogo interior no trabalhador. Ao se saber observado, este termina por sair do automatismo do cotidiano, fazendo-se questionamentos a respeito de sua prática. Por exemplo: "Talvez eu devesse ter feito assim" ou "Quando o pesquisador observou o meu colega, talvez ele tenha feito diferente" e etc. Tais questionamentos produzem um conhecimento sobre a atividade que se cria entre os trabalhadores e que seria inalcançável por qualquer observador externo.

A metodologia da clínica da atividade induz um deslocamento daquele que trabalha para o lugar de observador do seu próprio trabalho e visa dar um destino dialógico ao diálogo interior criado por ela. Em outras palavras, não só o analista do trabalho, mas o trabalhador é convocado a falar e, assim, pensar sobre a atividade, inclusive sobre as atividades não realizadas, que nem por isso deixam de estar presentes.

Deste modo, como a atividade real está para além da atividade realizada, o diálogo real não coincide com a relação que existe entre as réplicas no encadeamento do diálogo realizado (Clot, 2010a). Por meio do diálogo, o analista do trabalho busca, enquanto novo interlocutor, mobilizar a experiência estabilizada como meio de viver novas experiências e promover o desenvolvimento de novos recursos para a ação. Uma vez confrontados com as marcas do seu trabalho, os trabalhadores são convocados a falar de aspectos que não aparecem no registro feito, o que é invisível à atividade evidente. Com o foco naquilo que não converge entre as observações, a atividade do analista consiste em acompanhar tais dissonâncias e auxiliar os trabalhadores na comunicação do difícil de dizer, que toca o real da atividade.

51 Há uma dimensão de descoberta no decorrer deste percurso metodológico, pois o trabalhador é convocado a explicar sua atividade de uma forma que só ele pode fazer, colocando em debate não só a atividade realizada, mas também o real da atividade. Deste modo, por meio da metodologia é possível evidenciar a criação na atividade que se engendra no cotidiano de trabalho. 


\title{
5. Criação, imaginação e desenvolvimento
}

\subsection{A atividade de criação no cotidiano}

52 O conceito de atividade proposto por Clot remete diretamente ao de criação. Segundo Vigotski, a criação está presente na vida corriqueira das pessoas toda vez que o homem “(...) imagina, combina, modifica e cria algo novo, mesmo que esse novo se pareça a um grãozinho, se comparado às criações dos gênios” (2009, p. 14-15). A criação é então mais uma regra que uma exceção, sendo condição necessária da existência que se manifesta como aquilo que ultrapassa os limites da rotina. De acordo com o autor, a (re)combinação de elementos já representa algo novo.

53 A criação está intimamente relacionada com a atividade de imaginação. No início do processo de imaginação estão as percepções externas e internas que compõem a experiência humana e esta, por sua vez, é alimentada pela imaginação. "O que a criança vê e ouve ... são os primeiros pontos de apoio para sua futura criação. Ela acumula material com base no qual, posteriormente, será constituída a sua fantasia. Segue-se então um processo complexo de reelaboração desse material" (Vigotski, 2009, p. 36). Vigotski nega a ideia da imaginação como um divertimento ocioso da mente e busca enunciar leis gerais para o funcionamento da atividade imaginativa como desenvolvimento psicológico. É seguindo esta linha de compreensão que o autor relaciona imaginação e experiência.

\begin{abstract}
Deparamo-nos, então, com a primeira e a mais importante lei a que se subordina a atividade de imaginação. Essa lei pode ser formulada assim: a atividade criadora da imaginação depende diretamente da riqueza e da diversidade da experiência anterior da pessoa, porque essa experiência constitui o material com que se criam as construções da fantasia. Quanto mais rica a experiência da pessoa, mais material está disponível para a imaginação dela (2009, p. 22).
\end{abstract}

O desenvolvimento ocorre a partir da criação, tem como princípio a capacidade de combinar elementos antigos de novas maneiras. Porém, o entendimento comum dificilmente reconhece como produto da imaginação as pequenas invenções dos trabalhadores no cotidiano, dando destaque apenas àqueles que fizeram descobertas científicas notáveis, por exemplo. Vigotski afirma que qualquer invenção, grandiosa ou pequena, primeiro se constrói na mente pela imaginação. "Quem sabe quantas imaginações foram necessárias para que o arado, anteriormente um simples pedaço de pau com pontas calcinadas a fogo, se transformasse de um instrumento manual singelo no que é hoje (Vigotski, 2009, p. 14)". Destaca-se também o aspecto coletivo da criação humana, uma vez que as grandes invenções partem, necessariamente, do trabalho de inventores desconhecidos que foram aperfeiçoando seus instrumentos de trabalho.

A clínica da atividade também ressalta o caráter de inventividade inerente à atividade de trabalho. Maia (2006) apropria-se das concepções de Vigotski para fazer avançar os estudos sobre a atividade de trabalho. Ele destaca que, nessa perspectiva, "o trabalhador não é um autômato, mas que, indo além da execução da tarefa prescrita, faz uma dobra sobre a sua atividade, afirmando-se como um produtor criativo, ultrapassando o papel de simples reprodutor" (p. 37). 


\subsection{Desenvolvimento e criação}

O estudo da atividade visa encontrar, em cada situação de trabalho, algumas regularidades do processo de criação, neste caso entendido como processo de desenvolvimento. As regularidades da transformação da ação podem ser encontradas destacando o que permanece estável diante da multiplicidade das ações, sem eliminar as singularidades, comparando as diferenças, ou seja, estabelecendo os padrões do processo. Esta ideia pode parecer paradoxal, mas se trata de buscar aquilo que não varia dentro do que varia, isto é, as regularidades do desenvolvimento. Como afirma Clot (2008), a produção do novo é imprevisível, mas não é inexplicável.

Neste sentido, Clot se distancia da concepção de que a atividade é proveniente de esquemas operatórios invariantes, subjacentes à ação. Segundo seu argumento, a ação não é apenas o realizado, mas também libertação de seus pressupostos operatórios. 0 desenrolar da ação é relacionado ao real da atividade, situada em um campo de atividades possíveis e impossíveis que se expande para além das realizações imediatas. A via de entendimento não parte da abordagem da atividade como invariante operatória, mas da ideia de que toda atividade tem uma história e sua análise produz mudanças. Com isso, é possível dizer que o sentido da atividade não é constante para o sujeito, contudo, algo se repete e essa repetição traz variação, diferença que cria novos sentidos e possibilidades para a atividade.

\subsection{O movimento dialógico como condição de produção do novo}

Na intervenção proposta, o movimento dialógico gerado pelo método vai criar relações renovadas. Podemos dizer então que a motricidade dialógica é uma das condições de produção do novo, uma vez que o movimento oferece as circunstâncias favoráveis ao desenvolvimento discursivo pelo qual a atividade pode ser retrabalhada.

No decorrer de uma intervenção, uma nova combinação de elementos se faz presente na fala dos trabalhadores. Ao enfatizar as polêmicas do ofício, os debates de perspectivas explicitados pelos trabalhadores, o clínico da atividade provoca a análise. A atuação do clínico e/ou pesquisador, ao convocar o diálogo e confrontar as regras do ofício diante da imagem, estimula os protagonistas da atividade a gerar novas combinações desenvolvendo o gênero profissional.

O diálogo realizado no contexto do método é instigado a projetar-se para além de si mesmo, em referência a história do gênero, mas também para além dela, desenvolvendo-a coletivamente. Os problemas colocados pelo clínico demandam novas formas de pensar o ofício, ou seja, novas ideias: “Assim, a ideia que se produz no diálogo realizado é um acontecimento vivo que desenvolve o real do pensamento, um novo meio para pensar (Clot, 2010a, p. 246)."

61 Nesta perspectiva, parte-se do princípio que há um desenvolvimento possível no meio de trabalho que pode se realizar através da intervenção da clínica da atividade. 0 clínico - analista do trabalho - age no sentido de possibilitar a abertura de zonas de desenvolvimento iminente da atividade [4], o que pode viabilizar o enriquecimento do gênero profissional e assim a ampliação do poder de agir. No gênero há sempre uma certa estabilidade, uma consistência que coexiste com a plasticidade e a necessidade de reinvenção. $O$ gênero é sempre incompleto para dar 
conta dos desafios do trabalho e precisa variar, sendo alimentado pelos movimentos de criação, para permanecer vivo.

\section{A atividade do clínico da atividade na abertura da zona de desenvolvimento iminente}

63 A zona de desenvolvimento iminente (z.d.i) pode ser entendida como "brotos do desenvolvimento". Esse conceito surge em estudos acerca do mundo infantil. Enquanto o desenvolvimento real diz respeito aos problemas que a criança consegue resolver sozinha, o desenvolvimento iminente se explica por aquilo que a criança pode resolver com ajuda de outro. Vigotski chegou a tal concepção a partir do entendimento de que crianças com o mesmo nível de desenvolvimento real possuíam diferentes capacidades para resolver problemas com a ajuda do pesquisador.

A z.d.i. se define pela distância entre o nível de desenvolvimento real e o nível de desenvolvimento iminente. Esse conceito tem uma importante consequência para a relação entre a aprendizagem e o desenvolvimento, que consiste no fato de que o aprendizado antecede ao próprio processo de desenvolvimento. Com a participação de um outro mais experiente, é possível desempenhar ações que a mesma pessoa sozinha não seria capaz de fazer. 0 auxílio de pessoas mais experientes, como o professor na relação com a criança, desperta o desenvolvimento potencial do sujeito. Acerca do aprendizado anteceder-se ao desenvolvimento, Vigotski, nos estudos sobre pensamento e linguagem, assevera que no aprendizado da fala da criança, a fala surge primeiro como comunicação, no âmbito interpessoal, para só depois desenvolver-se como fala interior, ou seja, pensamento (Vigotski, 2002).

De modo semelhante ao que ocorre no desenvolvimento da fala na criança, também no diálogo entre o trabalhador e o analista do trabalho, há um âmbito interpsicológico de comunicação, o qual engendra um desenvolvimento intrapsicológico. 0 trabalhador provocado começa a utilizar a seu respeito as próprias formas de conduta que os outros haviam utilizado, em primeiro lugar, para com ele. Conforme descreve Clot:

\footnotetext{
A função do interveniente é, pois, central para re-mobilizar o diálogo do sujeito consigo mesmo, para solicitar os subdestinatários e para fazer "falar" as vozes interiores (Prot, 2006). Ele é o organizador de uma "retomada" dialógica (Siri, 2003): retomada do diálogo do sujeito com seu "já dito", retomada das palavras do outro e, finalmente, retomada das réplicas do sobredestinatário coletivo no e pelo discurso pessoal (Clot, 2010a, p. 251-152).
}

Ou seja, o outro se torna o instrumento psicológico da observação de si por si, cujo meio essencial é o diálogo interior.

Com base nisto, é preciso perceber outra regularidade dos processos de criação, a saber, a necessidade de uma apropriação de um gênero de atividades que funciona como sobredestinatário. Isto é, a apropriação das obrigações dialógicas, fixadas pelo dispositivo de intervenção, através da aparelhagem técnica e discursiva que permite acioná-lo. Isso porque a imagem não permite uma postura ilusória a respeito de uma relação direta e transparente com a atividade de trabalho. Ela é destinada a ser retificada graças à apropriação pelos sujeitos de um gênero de atividade dialógica que organiza a controvérsia sobre os dilemas da atividade comum. "A apropriação faz-se, assim, por "imitação" aqui entendida à maneira de Vigotski: como preparação para 
continuar sem o pesquisador o que os sujeitos começam a realizar com e em colaboração com o pesquisador" (Clot, 2010a, p. 246). Tal imitação não ocorre em mão única, uma vez que se trata de restaurar a função psicológica do coletivo comum de trabalho. Desse modo, os sujeitos observados passam a ser observadores de sua atividade. Quando os sujeitos apropriam-se deste gênero especializado, com ajuda do clínico, o trabalho realizado e observado através da imagem torna-se instrumento de troca entre os sujeitos de modo que novos instrumentos psicológicos do trabalho efetivo possam ser criados.

\section{Considerações Finais}

No percurso deste artigo, buscou-se indicar pistas acerca da criação no trabalho e caminhos que tornam possível intensificar e estudar a invenção neste meio. A análise indireta da atividade efetua um mapeamento das marcas do trabalho que revelam regularidades do processo de criação e ao mesmo tempo transformam a atividade. Isso porque tais marcas convocam um movimento dialógico criador de novas possibilidades de relações e sentidos, criador de novos recursos elaborados coletivamente para a criação no meio de trabalho.

69 O conceito de atividade desenvolvido na clínica da atividade está diretamente relacionado às elaborações de Vigotski (2009) acerca da criação. A criação está vinculada ao cotidiano da vida, sendo entendida como condição necessária da existência. Ela se dá através da (re)combinação de elementos que produz algo novo. Acompanhando esta nuance do pensamento de Vigotski, a clínica da atividade estabelece que a função psicológica do trabalho coloca o trabalhador como produto e produtor do processo criativo. É na atividade, como processo de criação, que são engendrados trabalho e trabalhador.

70 A análise da atividade vislumbra cartografar algumas regularidades do processo de criação no trabalho. O mapeamento é empreendido como um processo que evidencia as marcas do trabalho, convocando ao dialogismo e sua motricidade: fluxos de diálogos internos e externos sobre a atividade.

71 No cenário da intervenção em clínica da atividade, o movimento dialógico gerado cria novas possiblidades de relações e sentidos. Sendo assim, é possível ressaltar que a motricidade dialógica é uma das condições de produção do novo, uma vez que o movimento promove a conjuntura favorável ao desenvolvimento discursivo pelo qual a atividade pode ser retrabalhada, revisitada e ressignificada. Ocorre uma nova combinação de elementos que se faz presente na fala dos trabalhadores. Ao destacar os conflitos revelados pelo dispositivo de intervenção que expõe as marcas do trabalho, o analista provoca, nos protagonistas, a análise da ação sobre si mesmos.

72 A atuação do analista, ao convocar o diálogo e confrontar as regras do ofício diante do material produzido com os trabalhadores, estimula-os a gerar novas combinações que reverberam no gênero profissional. O diálogo realizado no contexto do método é instigado a projetar-se para além de si mesmo, em referência à história do gênero profissional, mas também para além dessa história, desenvolvendo-a coletivamente. Os problemas colocados pelo analista através da metodologia demandam novas formas de pensar o ofício, ou seja, desafios que forçam as fronteiras do gênero, impelindo ao surgimento de novas ideias, fomentando o desenvolvimento. 
73 compreensão desse processo. o clínico, ao observar a atividade do trabalhador, se coloca como destinatário de uma nova atividade do mesmo trabalhador - a de analisar seu próprio trabalho -, interferindo em seu diálogo interno. Este processo possibilita a abertura de zonas de desenvolvimento iminente da atividade (z.d.i).

Com isso, é possível dizer que, a partir da análise das marcas do trabalho, característica do método indireto, o profissional se observa e assume uma posição de protagonismo diante de sua atividade. $O$ analista do trabalho atua, nesse cenário, como coadjuvante, ou seja, como um dos instrumentos mediadores da análise. Por meio do diálogo, o novo interlocutor busca mobilizar a experiência estabilizada como meio de viver novas experiências e desenvolver novos recursos para a ação. Esses são alguns dos efeitos da abordagem em clínica da atividade.

\section{BIBLIOGRAFIA}

Alves, E. (2013). Trabalho: entre fios e ligações. Dissertação de mestrado, Universidade Federal Fluminense, Niterói.

Bakhtin, M. (2006). Os Gêneros do Discurso. In M. Bakhtin. Estética da Criação Verbal. (pp. 261-306). São Paulo: Martins Fontes.

Barros, J. P. (2012). Constituição de "sentidos" e "subjetividades": aproximações entre Vygotsky e Bakhtin. Ecos Estudos Contemporâneos de Subjetividade, 1,2, 134-146.

Barros, R.D.B. (1994). Grupo e Produção. In A. Lancetti (Org.), Saúde e loucura 4: grupos e coletivos (pp.145-154). São Paulo: Hucitec.

Bendassoli, P., \& Soboll, L. (2011). Introdução às clínicas do trabaho: aportes teóricos, pressupostos e aplicações. In P. Bendassoli, \& L. Soboll (Orgs.), Clínicas do trabalho (pp. 3-21). São Paulo: Atlas.

Brito, J. (2004). Saúde do trabalhador: reflexões a partir da abordagem ergológica. In M.

Figueiredo, M. Athayde, J. Brito, \& D. Alvarez (Orgs.), Labirintos do trabalho: interrogações e olhares sobre o trabalho vivo (pp. 91-114). Rio de Janeiro: DP\&A.

Coimbra, C. (1995). Os caminhos de Lapassade e da análise institucional. Revista do Departamento de Psicologia da Universidade Federal Fluminense, 7, 1, 52-80.

Clot, Y. (1981). Présentation. In I. Oddone, A. Re, \& G. Briante, Redécouvrir l'expérience ouvrière. Paris: Editions Sociales.

Clot, Y. (2007). A função psicológica do trabalho (2.ed.). Petrópolis: Vozes.

Clot, Y. (2008). Le recherche fondamentale de terrain: une troisième voie. Education permanente. 177, 67-78.

Clot, Y. (2010a). Trabalho e Poder de Agir. Belo Horizonte: Fabrefactum.

Clot, Y. (2010b). A psicologia do trabalho na França e a perspectiva da clínica da atividade. Fractal: Revista de Psicologia, 22, 1, 207-234.

Laboreal, Volume $11 \mathrm{~N}^{\circ} 1$ | 2015 
Clot, Y. \& Faïta, D. (2000). Genres et styles en analyse du travail. Concepts et méthodes. Travailler, 4, 7-41.

Dadalto, C. F., Vasconcelos, C. M., Santos, C. M. L., Rosemberg, D. S., Archanjo, J. V. L., \& PetinelliSouza, S. (2011). O vídeo produzindo encontros e confrontos para uma clínica da atividade docente. In D. S. Rosemberg, J. Ronchi Filho, \& M. E. B. Barros (Orgs.), Trabalho docente e poder de agir: clínica da atividade, devires e análises (99-144). Vitória: EDUFES.

Faïta, D. (2007). L'image animée comme artefact dans le cadre méthodologique d'une analyse clinique de l'activité. Activités, 4, 2, 3-15.

Faïta, D. (2013). Dialogismo. Laboreal, 9, 1, 113-116.

Fernandez, G. \& Clot, Y. (2007). Entrevistas en auto-confrontación: un método en clínica de la actividad. Laboreal, 3, 1, 15-19.

Leplat, J. (1980). La Psychologie ergonomique. Paris: PUF.

Louback, A. (2013). A atividade de coleta de lixo uma análise na perspectiva da clínica da atividade. Dissertação de mestrado, Universidade Federal Fluminense, Niterói.

Martins, M. S (2009). Hibridismo e plasticidade na constituição dos gêneros do discurso. Trabalhos em Linguística Aplicada, 48, 1, 23-29.

Maia, M. (2006). o corpo invisível do trabalho: Cartografia dos Processos de Trabalho em Saúde. Dissertação de Mestrado, Universidade Federal Fluminense, Niterói.

Mendes, R. \& Dias, E.C. (1991). Da medicina do trabalho à saúde do trabalhador. Revista de Saúde Pública, 25, 5, 341-349.

Minayo-Gomez, C. (2011). Campo da saúde do trabalhador: trajetória, configuração e transformações. In C. Minayo-Gomez, H.M.H. Machado, \& P.G.L. Pena (Orgs.), Saúde do trabalhador na sociedade contemporânea brasileira (pp. 23-34). Rio de Janeiro: Fiocruz.

Neves, M.Y., Seligmann-Silva, E. \& Athayde, M. (2004). Saúde mental e trabalho: um campo de estudo em construção. In A. Araújo, M.F. Alberto, M.Y. Neves \& M. Athayde (Orgs.), Cenários do trabalho: subjetividade, movimento e enigma (pp. 19-49). Rio de Janeiro: DP\&A.

Osorio, C. (2010). Experimentando a fotografia como ferramenta de análise da atividade de trabalho. Revista Informática na Educação: teoria e prática. 13, 1, 41-49.

Osorio, C. (2011). A fotografia como uma marca do trabalho: um método que convoca o protagonismo do trabalhador na invenção de mundo. In A. Zanella, \& J. Tittoni (Org), Imagens no pesquisar: experimentações (pp. 211-226). Porto Alegre: Ed. Dom Quixote.

Osório da Silva, C., Souto, A. P., \& Memória-Lima, K. M. N. (2015). A pesquisa-intervenção em Psicologia do Trabalho em um aporte que toma o desenvolvimento como método e objeto. Fractal: Revista de Psicologia, 27, 1, 12-15.

Pacheco, A. B., Barros, M. E. B., \& Osorio da Silva, C. (2013). Trabalhar o mármore e o granito entre cores e ritmos. Cadernos de Psicologia Social do Trabalho, 13, 2, 255-270.

Prestes, Z (2012). Quando não é quase a mesma coisa.Traduções de Lev Semionovitch Vigotski no Brasil. Campinas: Editores Associados.

Rosemberg, D. S., Ronchi Filho, J., \& Barros, M. E. B. (Orgs.). (2011). Trabalho docente e poder de agir: clínica da atividade, devires e análises. Vitória: EDUFES.

Smolka, A. L. (2009). Apresentação e comentários. In L. Vigotsky, Imaginação e criação na infância: ensaio psicológico: livro para professores. São Paulo: Ática. 
Souza, V. L. I. (2012). Entre Intensidades do Trabalho: uma clínica da atividade nas tramas da Oficina de Criatividade do Hospital Psiquiátrico. Dissertação de Mestrado, Universidade Federal do Rio Grande do Sul, Porto Alegre.

Teixeira, D. V. (2008). Experimentação em Clínica da Atividade: cartografias na escola. Dissertação de Mestrado. Universidade Federal do Espírito Santo.

Vigotsky, L. (1996). Teoria e método em psicologia. São Paulo: Martins Fontes.

Vigotsky, L. (2002). A Formação Social da Mente. São Paulo: Marins Fontes.

Vigotsky, L. (2009). Imaginação e criação na infância: ensaio psicológico: livro para professores (Z. Prestes, Trad.; A. L. Smolka, Apresentação e comentários). São Paulo: Ática.

Zanella, A. V (2007). Vygotski: contexto, contribuições à psicologia e o conceito de zona de desenvolvimento proximal. Itajaí: Ed. Univali.

Zanella, A.V., Reis, A. C., Titon, A. P., Urnau, L. C., \& Dassoler, T. R. (2007). Questões de método em textos de Vygotski: contribuições à pesquisa em psicologia. Psicologia \& Sociedade, 19, 2, 25-33.

\section{NOTAS}

1. Os registros de falas se dão nas Instruções ao Sósia (Clot, 2007, 2010a). Os registros em vídeo, nas Autoconfrontações Cruzadas, têm sido os mais investidos nos estudos franceses atuais (Clot, 2007, 2010a) e também são usados no Brasil (ver, por exemplo, Dadalto et al., 2011). As fotos têm sido usadas como mediador no Brasil, sobretudo nos grupos de pesquisa NUTRAS - UFF (Osório da Silva, Souto, \& Memória-Lima, 2015) e NEPESP-UFES (Rosemberg, Ronchi Filho, \& Barros, 2011).

2. A proposição da noção de poder de agir se faz a partir de uma perspectiva espinosista. Os autores dão essa explicação em um rodapé do artigo Genres et styles en analyse du travail. Concepts et méthodes, publicado em 2000, na revista Travailler. Na introdução do livro Trabalho e poder de agir a referência à Espinosa é retomada de forma mais clara.

3. Em seus estudos sobre a grupalidade, Barros afirma que "Se tomarmos o grupo como dispositivo acionamos nele sua capacidade de se transformar... fazer emergir um território existencial não mais da ordem do individual (seja aqui de um indivíduo ou de um grupo), mas da ordem do coletivo." (1994, p. 132).

4. Também referido como "zona de desenvolvimento proximal" na tradução brasileira dos livros de Yves Clot $(2007,2010)$. Nossa opção pelo termo "iminente" acompanha a pesquisa de Zoia Prestes (2012), especialista na tradução de Vigotski diretamente do russo para a língua portuguesa.

\section{RESUMOS}

Este artigo discute a metodologia da clínica da atividade. São analisados aspectos que apontam para a abertura dialógica possibilitada por esta abordagem, que viabiliza a criação de novos recursos para a atividade de trabalho, bem como a produção de conhecimento sobre esse processo de criação. Ressalta-se o modo pelo qual a metodologia dialógica e indireta pode desenvolver tais condições. O diálogo entre trabalhador(es) e o analista do trabalho pode 
mobilizar a experiência estabilizada como meio de viver novas experiências e assim propiciar o desenvolvimento de novos recursos para a ação. Articulam-se os métodos utilizados pela clínica da atividade com a psicologia vigotskiana, empreendendo a discussão acerca dos conceitos de criação e desenvolvimento.

Este artículo discute la metodología de la clínica de la actividad. En el se analizan los aspectos que apuntan a la apertura dialógica posibilitada por dicho enfoque, el cual permite la creación de nuevos recursos para la actividad de trabajo, así como para la producción de conocimiento sobre ese proceso. Se hace énfasis en el modo por el cual la metodología dialógica e indirecta puede favorecer tales condiciones. El diálogo entre trabajador(es) y analista del trabajo puede movilizar la experiencia estabilizada como medio para vivir nuevas experiencias y así propiciar el desarrollo de nuevos recursos para la acción. Se articulan los métodos utilizados por la clínica de la actividad con la psicología vigotskiana, emprendiendo la discusión acerca de los conceptos de creación y desarrollo.

Cet article discute la méthodologie de la clinique de l'activité. On y analyse des aspects qui révèlent l'ouverture dialogique rendue possible par cette approche, en permettant la création de nouvelles ressources pour l'activité de travail, mais aussi la production de connaissances à propos de ce processus de création. On souligne le moyen par lequel la méthodologie dialogique et indirecte permet de développer de telles conditions. Le dialogue entre les travailleurs et l'analyste du travail peut mobiliser l'expérience stabilisée comme moyen de vivre de nouvelles expériences et rendre possible le développement de nouvelles ressources pour l'action. On articule les méthodes dont se sert la clinique de l'activité avec la psychologie vygotskienne en reprenant la discussion concernant les concepts de création et de développement.

This paper discusses the methodology of the activity clinic. The aspects under analysis point to the dialogue enabled by this approach, which makes it feasible to create new resources for the labour activity, as well as the production of knowledge about that creation process. It highlights the method this indirect dialogue methodology may follow to develop such conditions. The dialogue between the worker(s) and the labour analyst can mobilise the established experience as a way to live new experiences and thus favour the development of new resources for action. It combines the methods used by the activity clinic with the Vygotskian psychology, hence fostering a debate concerning the creation and development concepts.

\section{ÍNDICE}

Mots-clés: clinique de l'activité, méthodologie, travail, création, développement

Palavras-chave: clínica da atividade, metodologia, trabalho, criação, desenvolvimento

Palabras claves: clínica de la actividad, metodología, trabajo, creación, desarrollo

Keywords: activity clinic, methodology, work, creation, development

\section{AUTORES}

\section{ALICE PAIVA SOUTO}

Núcleo de Estudos e Intervenção em Trabalho e Saúde (NUTRAS), Programa de Pós Graduação em Psicologia, Departamento de Psicologia - Instituto de Psicologia, Universidade Federal Fluminense, Rua Santa Cristina, 49/203 , Santa Teresa, Rio de Janeiro - RJ, CEP: 20241250, Brasil ally_paiva@yahoo.com.br 


\section{KARLA MARIA NEVES MEMÓRIA LIMA}

Núcleo de Estudos e Intervenção em Trabalho e Saúde (NUTRAS), Programa de pós graduação em psicologia, Departamento de Psicologia - Instituto de Psicologia, Universidade Federal Fluminense, Rua Tonelero, 125/802. Copacabana, CEP: 22030-001. Rio de Janeiro - RJ , Brasil karla.memoria@gmail.com

\section{CLAUDIA OSORIO DA SILVA}

Núcleo de Estudos e Intervenção em Trabalho e Saúde (NUTRAS), Programa de pós graduação em psicologia, Departamento de Psicologia - Instituto de Psicologia, Universidade Federal Fluminense, Rua São Manuel, 23 apt 201. Botafogo, Rio de Janeiro - RJ, Brasil claudia.osorio.uff@gmail.com 